\title{
Palladium-catalyzed diastereo- and enantioselective allylic alkylation of oxazolones with 1,3-dienes under base-free conditions
}

\author{
Haijian Yang and Dong Xing*
}

Shanghai Engineering Research Center of Molecular Therapeutics and New Drug Development, School of Chemistry and Molecular Engineering, East China Normal University, 3663 North Zhongshan Rd., Shanghai, 200062, China.

E-mail: dxing@sat.ecnu.edu.cn

Herein, we report a highly diastereo- and enantioselective allylic alkylation of oxozolones with 1,3-dienes by palladium-hydride catalyst under base-free conditions. With DTBM-SEGPHOS as the chiral ligand, a series of enantioenriched oxazolones bearing tertiary carbon centers were synthesized from substituted 1,3-dienes via exclusive 1,2-addition with moderate to good diastereoselectivities and high enantioselectivities. When simple 1,3-butadiene was used as the allyl precursor under this base-free catalytic system, 1,4-addition products were obtained in good yields with high regioselectivities.

Transition metal-catalyzed asymmetric allylic alkylation (AAA) of carbon-based pronucleophiles is a powerful tool for the enantioselective construction of $\mathrm{C}-\mathrm{C}$ bonds. ${ }^{1}$ In recent years, significant progress has been made on the use of unsaturated hydrocarbons, such as allenes, alkynes and 1,3dienes, as atom-economic allyl precursors for AAAs. ${ }^{2-4}$ Among them, 1,3-dienes have gained considerable attention dating back to 1970 s when Hata et al. reported the palladium-catalyzed addition of 1,3-dicarbonyl compounds to 1,3 -dienes. ${ }^{5}$ Following this pioneering report, different transition metal catalysts such as $\mathrm{Pd}, \mathrm{Ni}$, Rh etc have been substantially used as the transition metalhydride $(\mathrm{M}-\mathrm{H})$ precursors to convert 1,3-dienes into electrophilic metal- $\pi$-allyl species, which then react with pronucleophiles for efficient C-C formations (Scheme 1a). ${ }^{2 c, 4 f-k}$ In 2004, Hartwig's group reported the first enantioselective example of such type on a palladium-catalyzed addition of 1,3- 
diketones to 1,3-dienes with JosiPhos ligand. ${ }^{4 f}$ Since then, AAAs of different carbon-based pronucleophiles with 1,3-dienes have gained rapid progress. Meek et al. developed a chiral (CDC)Rh-catalyzed AAA of indoles with 1,3-dienes. ${ }^{49}$ Zhou and coworkers reported a nickel-hydridecatalyzed asymmetric $\alpha$-allylic alkylation of ketones with 1,3-dienes with a chiral SEGPHOS-type ligand. $^{\text {th }}$ By using Pd-phosphinooxazoline (Pd-PHOX) catalysts, Malcolmson and co-workers accomplished the AAAs of various activated carbon-based nucleophiles such as Meldrum's acids or malononitriles with 1,3-dienes with high enantioselectivity. ${ }^{4 i, 4 j}$ Very recently, Zi and co-workers developed a stereodivergent AAA of aldimine esters by synergistically combining Pd-PHOX and $\mathrm{Cu}$ catalysts to access all four stereoisomers of the alkylation products. ${ }^{4 k}$ For these palladium-catalyzed asymmetric transformations (Scheme $1 \mathrm{~b}$ ), the $\mathrm{Pd}$-PHOX precatalyst has to be pre-formed and excess amounts of amine-based organic bases (2-3 equiv) were essential. With the aim to develop AAAs of versatile carbon-based pronucleophiles with a broad scope of 1,3-dienes, the exploration of mild and novel catalytic asymmetric system remains an urgent task in this area.

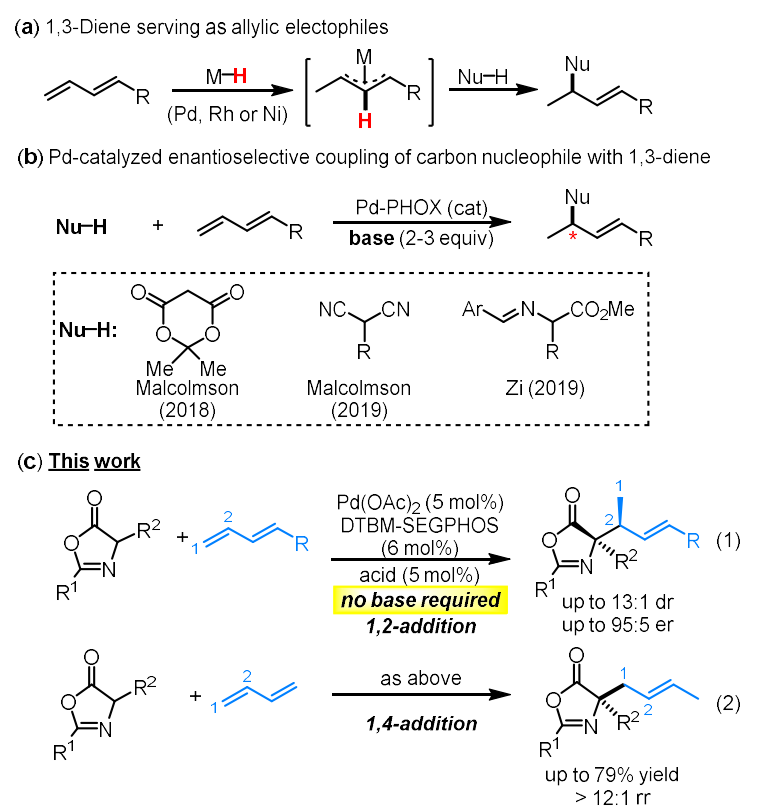

Scheme 1 Palladium-catalyzed asymmetric allylic alkylation of various carbon-based nucleophiles with 1,3-dienes 
Oxazolones have been widely used as good nucleophiles in a number of AAAs with either conventional allyl agents $^{6}$ or atom-economic allyl precursors. ${ }^{7}$ The resulted allylic alkylated oxazolones bearing tertiary carbon centers are valuable precursors of biologically important chiral quaternary amino acids. ${ }^{8}$ Although the racemic example for the allylic alkylation of oxazolone with 1,3-dienes have been reported by Meek and co-workers by using a (CDC)-Rh catalyst, ${ }^{9}$ the asymmetric version of such transformation has not been reported. During our exploration toward the different reactivities of 1,3-dienes under metal-hydride catalysis, ${ }^{10}$ we found that a palladium(II) acetate \& camphorsulfonic acid precatalytic system, together with a chiral SEGPHOS ligand, has allowed an efficient AAA of oxazolones with substituted 1,3-dienes in an exclusive 1,2-addition manner with moderate to good diastereoselectivities and high enantioselectivities under base-free conditions (Scheme 1c, eq 1). In addition, when simple 1,3-butadiene was used as the allyl precursor under this base-free catalytic system, 1,4-addition products were obtained in good yields with high regioselectivities (Scheme 1c, eq 2).

Table 1 Condition Optimization

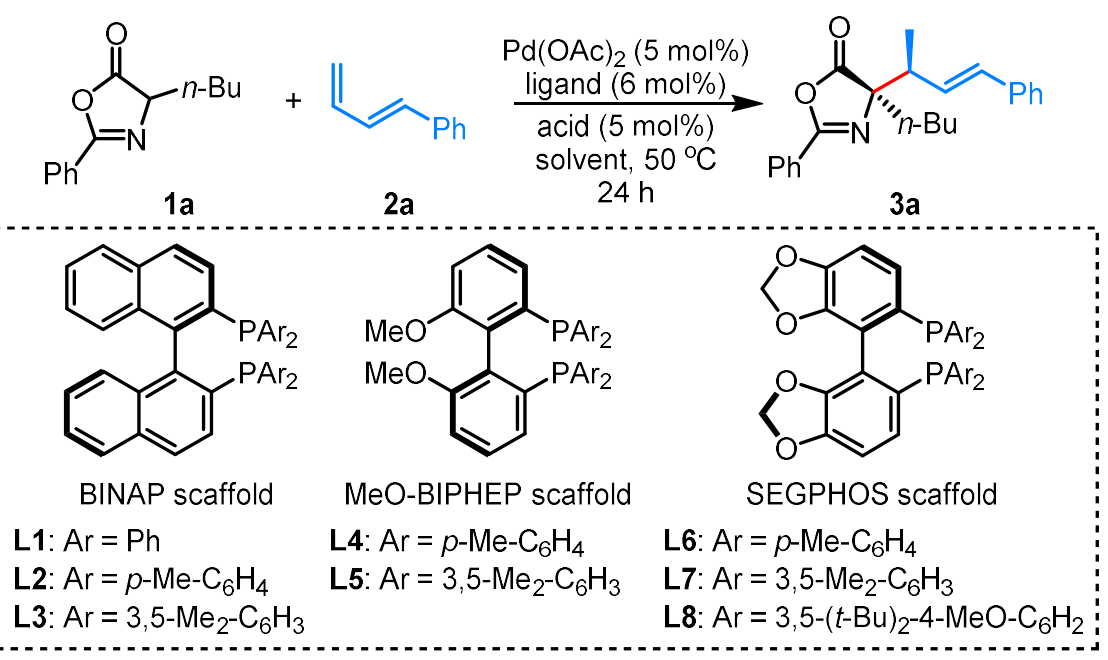




\begin{tabular}{ccccccc}
\hline entry & ligand & acid & solvent & yield $(\%)^{b}$ & $\mathrm{dr}^{c}$ & $\mathrm{er}^{d}$ \\
\hline $1^{e}$ & L1 & TsOH & THF & 31 & $2: 1$ & $90: 10$ \\
$2^{e}$ & L1 & PhCOOH & THF & 50 & $6: 1$ & $63: 37$ \\
$3^{e}$ & L1 & Ph $_{2} P O O H$ & THF & 59 & $6: 1$ & $78: 22$ \\
$4^{e}$ & L1 & CSA & THF & 46 & $8: 1$ & $90: 10$ \\
$5^{e}$ & L1 & CSA & 1,4-dioxane & 59 & $6: 1$ & $78: 22$ \\
$6^{e}$ & L1 & CSA & CPME & 70 & $8: 1$ & $75: 25$ \\
7 & L1 & CSA & THF & 70 & $8: 1$ & $90: 10$ \\
8 & L2 & CSA & THF & 84 & $8: 1$ & $73: 27$ \\
9 & L3 & CSA & THF & 85 & $8: 1$ & $61: 39$ \\
10 & L4 & CSA & THF & 55 & $7: 1$ & $90: 10$ \\
11 & L5 & CSA & THF & 63 & $5: 1$ & $60: 40$ \\
12 & L6 & CSA & THF & 67 & $10: 1$ & $90: 10$ \\
13 & L7 & CSA & THF & 70 & $7: 1$ & $58: 42$ \\
14 & L8 & CSA & THF & 81 & $10: 1$ & $93: 7$ \\
15 & L8 & -- & THF & $<5$ & -- & -- \\
\hline
\end{tabular}

${ }^{a}$ Unless otherwise noted, the reactions were run in $0.1 \mathrm{mmol}$ scale of 2a. 1a (1.2 equiv), $\mathrm{Pd}(\mathrm{OAc})_{2}(5$ mol\%), ligand (6 mol\%), acid (5 mol\%), solvent $(0.2 \mathrm{~mL}) .{ }^{b}$ Isolated yield of the major diastereomer. ${ }^{c}$ Diastereoselective ratio(dr) was determined by ${ }^{1} \mathrm{H}$ NMR spectroscopy of the crude reaction mixture. ${ }^{d}$ Enantioselective ratio (er) was determined by chiral HPLC analysis. ${ }^{e} 20 \mathrm{~mol} \%$ of the acid was used.

We started our initial investigation by using oxozolone $1 \mathbf{a}$ and 1 -phenylbutadiene $\mathbf{2 a}$ as the model substrates. In the presence of $5 \mathrm{~mol} \%$ of $\mathrm{Pd}(\mathrm{OAc})_{2}$ and 6 mol\% of ( $R$ )-BINAP (L1), several acid cocatalysts were firstly examined with THF as the solvent. When $\mathrm{TsOH}$ was employed as the $\mathrm{Pd}-\mathrm{H}$ precursor, the desired allylic substitution product 3a was obtained in moderate yield with 2:1 dr. To our delight, high enantioselective ratio (90:10 er) was observed for the major diastereomer (Table 1, entry 1). Using benzoic acid or diphenylphosphinic acid resulted improved yield and dr of $\mathbf{3 a}$, but with decreased er (Table 1, entries 2 and 3). When camphorsulfonic acid (CSA) was employed, 3a was obtained with 8:1 dr and 90:10 er (Table 1, entry 4). Changing the solvent from THF to 1,4dioxane or CPME showed no improvement (Table 1, entries 5 and 6). Interestingly, when the amount of CSA was decreased from 20 to 5 mol $\%$, the yield of 3 a was increased from $46 \%$ to $70 \%$ while the stereoselectivity remained unattached (Table 1, entry 7 vs entry 4). With CSA as the choice of acid, 
different chiral bidentate phosphine ligands were screened. While the BINAP-type ligand ToIBINAP (L2), xyIBINAP (L3) and the MeO-BIPHEP-type ligand L4 and L5 failed to give satisfactory results in balancing both the efficiency and the stereoselectivity, using SEGPHOS-type ligand such as L6 or L8 allowed this transformation to proceed with high stereoselectivity while the reaction efficiency was maintained (Table 1, entries 8-14). The best result was achieved when DTBM-SEGPHOS (L8) was used as the ligand, yielding 3a in 81\% isolated yield with 10:1 dr and 93:7 er (Table 1, entry 14). Finally, in the absence of the acid catalyst, the formation of 3a was not observed (Table 1, entry 15).

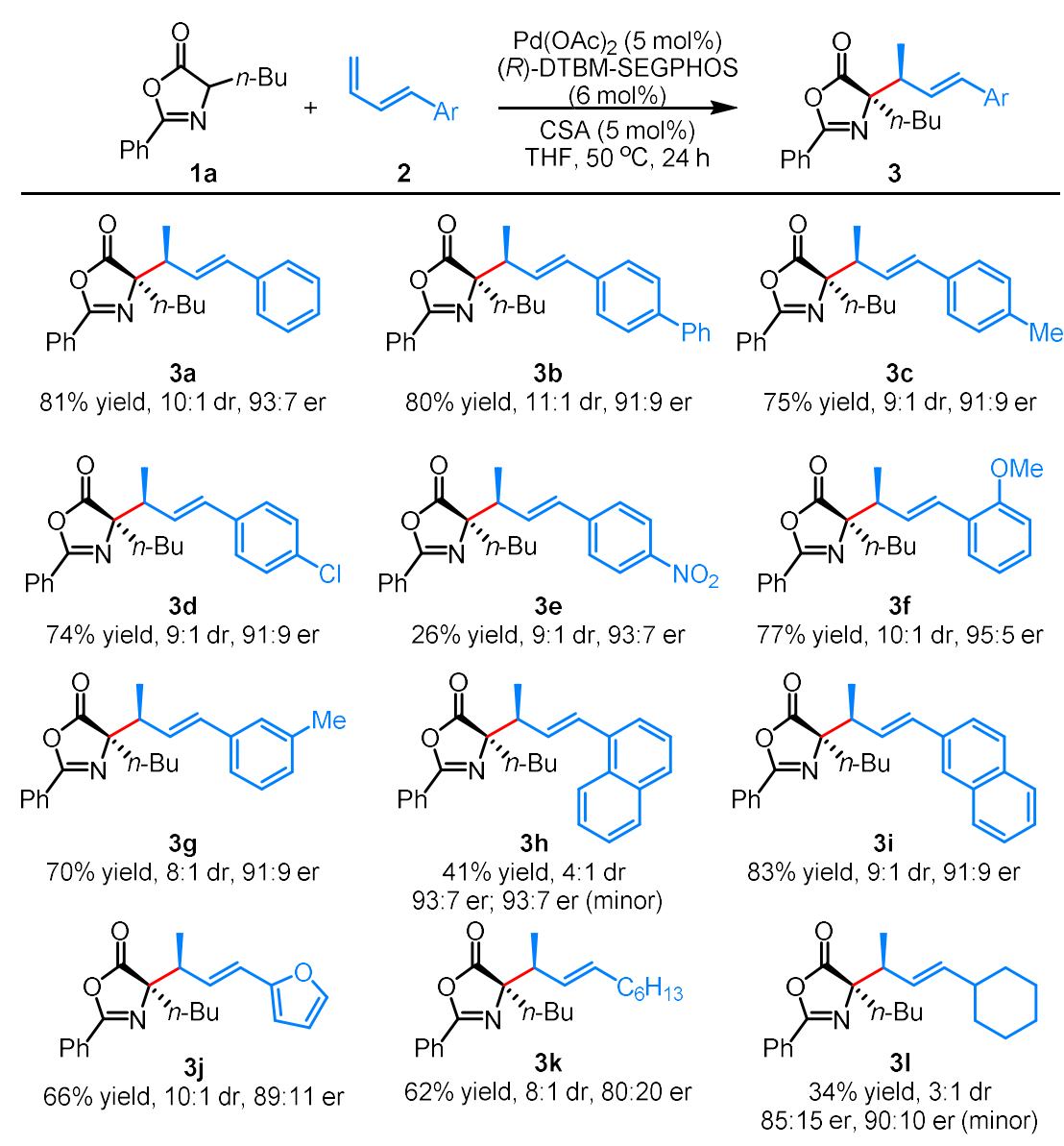

Scheme 2 Substrate scope of 1,3-dienes (all reactions were run in $0.2 \mathrm{mmol}$ scale of 2, $1 \mathrm{a}$ (1.2 equiv), Pd(OAc)2 (5 mol\%), (R)-DTBM-SEGPHOS (6 mol\%), CSA (5 mol\%), THF (0.2 mL); Isolated yield of the major diastereomer; Diastereoselective ratio(dr) was determined by $1 \mathrm{H}$ NMR spectroscopy of the crude reaction mixture; Enantioselective ratio (er) was determined by chiral HPLC analysis. 
With the optimized reaction conditions in hand, the generality of this enantioselective allylation was investigated (Scheme 2). Different substituted 1,3-dienes were tested first. Aryl substituted 1,3dienes bearing phenyl, methyl or chloro-substitutions at para position on the aryl ring gave the corresponding allylation products in good yields with high $\mathrm{dr}$ and er $(\mathbf{3 b} \mathbf{- 3} \mathbf{\mathbf { d }})$, however, strong electron-withdrawing group such as nitro group resulted much diminished yield but the stereoselectivity was maintained (3e). Aryl 1,3-dienes bearing electron-donating metasubstitutions on the aryl ring also yielded the desired product in good efficiency and high stereoselectivity (3f, $\mathbf{3 g}$ ). While 2-naphthyl substituted 1,3-diene led to the corresponding product in good yield with high dr and er (3i), 1-naphthyl substituted one showed only moderate reactivity and diastereoselectivity but both diastereomers were formed with high enantiopurity (3h). ${ }^{11} 2$-Furyl substituted 1,3-diene reacted smoothly with $\mathbf{1} \mathbf{a}$ to give desired product $\mathbf{3} \mathbf{j}$ in good yield with high dr and er. Alkyl substituted 1,3-dienes were also suitable substrates. Hexyl substituted 1,3-diene gave the product $\mathbf{3 k}$ in 62\% yield with 8:1 dr and 80:20 er. On the other hand, cyclohexyl substituted substrate showed low efficiency, giving the corresponding product 3I in 32\% yield with 3:1 dr but again, with high enantioselective control for both diastereomers. 

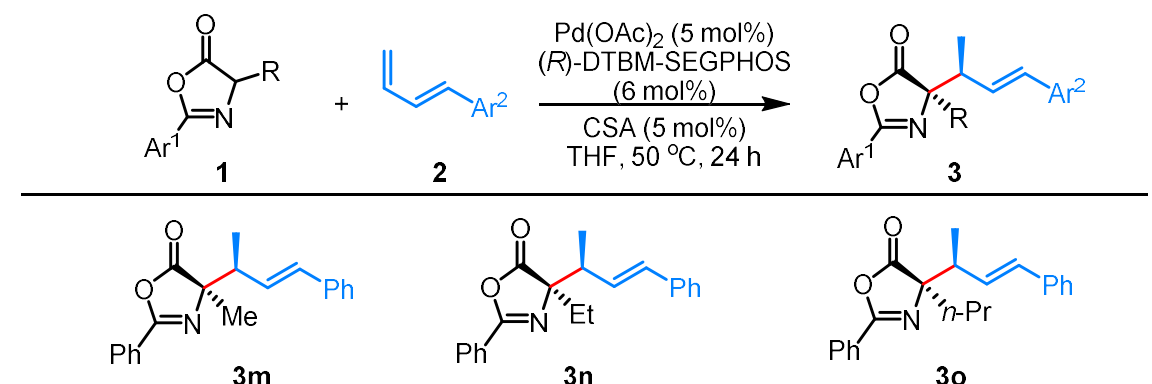

$63 \%$ yield, $8: 1 \mathrm{dr}, 91: 9 \mathrm{er}$

$52 \%$ yield, $8: 1 \mathrm{dr}, 92: 8 \mathrm{er}$
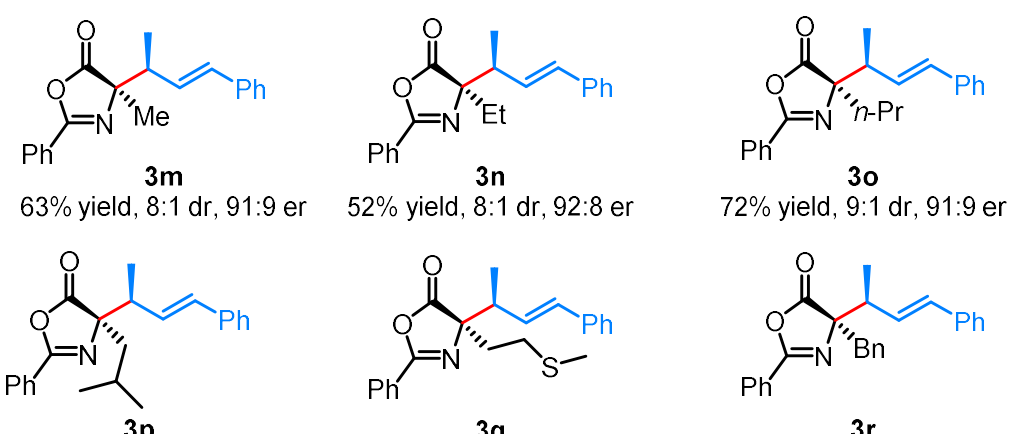

$52 \%$ yield, $8: 1 \mathrm{dr}, 93: 7 \mathrm{er}$

$72 \%$ yield, $9: 1 \mathrm{dr}, 91: 9 \mathrm{er}$

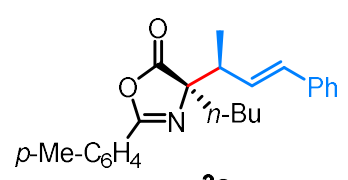

45\% yield, $8: 1 \mathrm{dr}, 93: 7 \mathrm{er}$

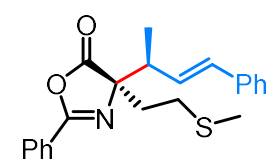

$3 q$

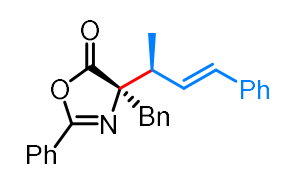

$3 r$

$37 \%$ yield, $8: 1 \mathrm{dr}, 86: 14 \mathrm{er}$

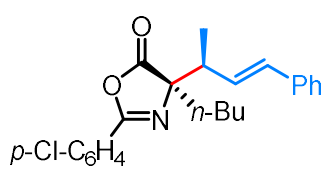

$3 t$

$46 \%$ yield, $13: 1 \mathrm{dr}, 92: 8 \mathrm{er}$

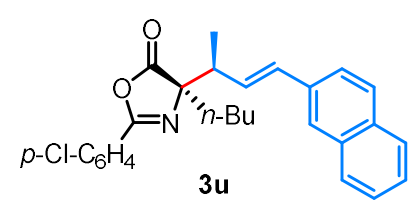

$41 \%$ yield, 8:1 dr, 93:7 er

Scheme 3 Substrate scope of oxazolones (all reactions were run in $0.2 \mathrm{mmol}$ scale of 2, 1 (1.2 equiv), $\mathrm{Pd}(\mathrm{OAc}) 2$ (5 mol\%), (R)-DTBM-SEGPHOS (6 mol\%), CSA (5 mol\%), THF (0.2 mL); Isolated yield of the major diastereomer; Diastereoselective ratio(dr) was determined by $1 \mathrm{H}$ NMR spectroscopy of the crude reaction mixture; Enantioselective ratio (er) was determined by chiral HPLC analysis.

The substrate scope of oxazolones was then investigated (Scheme 3). Various alkyl substituents at the C4 position of oxazolones were well tolerated to undergo the enantioselective allylic alkylation reaction, providing the corresponding products bearing tertiary stereogenic centers in moderate to good yields with high level of diastereo- and enantioselectivities ( $3 m-3 r)$. Oxazolones bearing para-substituted phenyl group at the $\mathrm{C} 2$ position also underwent the desired reaction with high $d r$ and er but in moderate yields $(3 \mathbf{s}-\mathbf{3 t})$.

The resulted optically active oxazolone products could be utilized as precursors for the synthesis of $\alpha, \alpha$-disubstituted unnatural amino acids. To demonstrate their synthetic utilities, oxazolone $3 a$ was treated with $\mathrm{K}_{2} \mathrm{CO}_{3}$ in $\mathrm{MeOH}$ to access the benzoyl-protected enantioenriched $\alpha, \alpha$ disubstituted amino ester 4 in 91\% yield. On the other hand, acid hydrolysis of $3 a$ led to the 
corresponding benzoyl-protected amino acid 5 in 83\% yield while the enantiomeric level was maintained (Scheme 4).

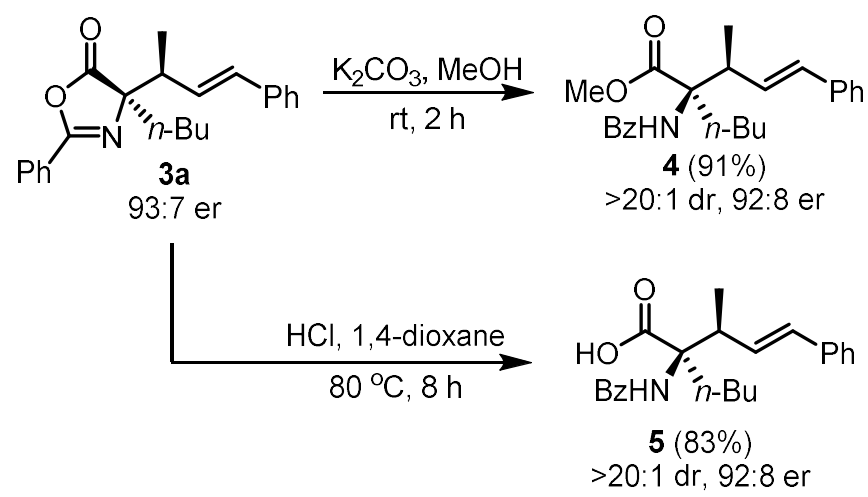

Scheme 4 Synthetic elaborations of compound 3a

Allylic alkylation reactions utilizing 1,3-dienes generally occurred via 1,2-addition, and regioselective allylic alkylation via 1,4-addition was seldom reported. ${ }^{12}$ As an important chemical feedstock, simple 1,3-butadiene has found wide applications in a number of useful transformations. ${ }^{13}$ However, using 1,3-butadiene as the metal- $\pi$-allyl precursor to react with pronucleophiles was challenging owing to their nature to undergo rapid telomerization under metal catalysis. ${ }^{14}$ In view of the base-free nature of the current catalytic system, which might reduce the tendency for 1,3-butadiene to undergo telomerization, the reactivity between oxazolone and 1,3butadiene was explored. To our delight, under standard reaction conditions, the 1,4-addition product, rather than a 1,2-addition product generally observed for substituted 1,3-dienes, were obtained in good yields with high regioselectivities (Scheme 5). ${ }^{15}$ the excellent regioselectivity for this transformation would offer a useful protocol for the crotylation of other type of pronucleophiles. 

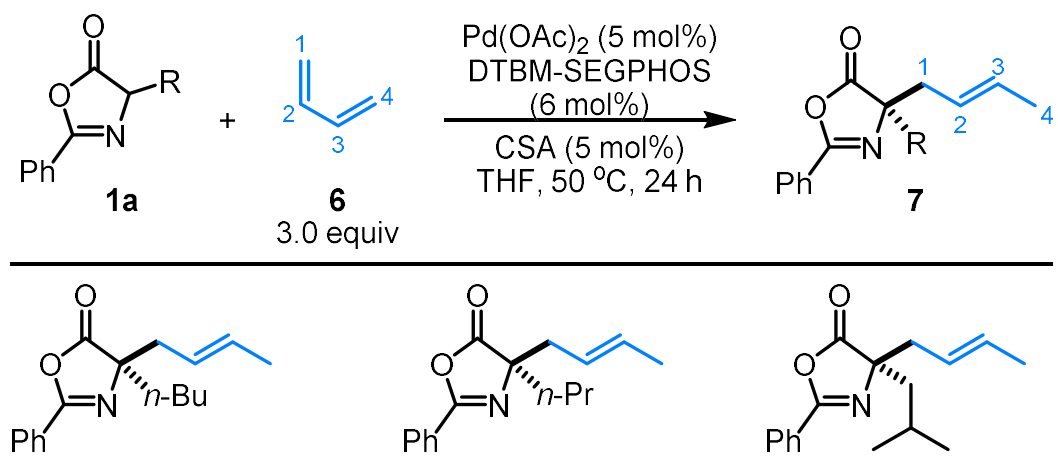

7a, $79 \%, 12: 1 \mathrm{rr}$

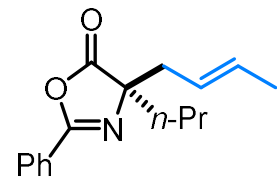

7b, $76 \%, 13: 1 \mathrm{rr}$

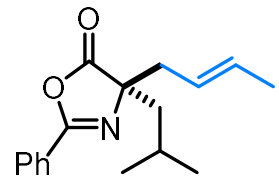

7c, $74 \%, 13: 1 \mathrm{rr}$

Scheme 5 Allylic alkylation of oxazolones with 1,3-butadiene via 1,4-addition.

In conclusion, we have developed a palladium-catalyzed diastereo- and enantioselective allylic alkylation of oxazolones with 1,3-dienes under base-free conditions. A palladium-hydride catalyst generated from $\mathrm{Pd}(\mathrm{OAc})_{2}$ and camphorsulfonic acid is response for the activation of 1,3-dienes. With DTBM-SEGPHOS as the chiral ligand, a series of oxazolones bearing tertiary carbon centers were synthesized from substituted 1,3-dienes with moderate to good diastereoselectivities and high enantioselectivities. This base-free catalytic system is also applicable to simple 1,3-butadiene but yielding 1,4-addition product exclusively. Further development of asymmetric transformations with this catalytic system is currently ongoing.

\section{REFERENCES}

1 For selected reviews, see: (a) B. M. Trost and D. L. Van Vranken, Chem. Rev., 1996, 96, 395-422; (b) B. M. Trost and M. L. Crawley, Chem. Rev., 2003, 103, 2921-2944; (c) S. L. You and L. X. Dai, Angew. Chem. Int. Ed., 2006, 45, 5246-5248; (d) Z. Lu and S. Ma, Angew. Chem. Int. Ed., 2008, 47, 258-297; (e) Z. Lu and S. Ma, Angew. Chem. Int. Ed., 2008, 47, 258-297; (f) S. L. Rössler, D. A. Petrone and E. M. Carreira, Acc. Chem. Res., 2019, 52, 2657-2672; (g) Q. Cheng, H.-F. Tu, C. Zheng, J.-P. Qu, G. Helmchen and S.-L. You, Chem. Rev., 2019, 119, 1855-1969. 
2 For selected reviews on atom-economy, see: (a) B. Trost, Science, 1991, 254, 1471-1477; (b) R. A. Sheldon, Pure Appl. Chem., 2000, 72, 1233-1246; (c) T. Newhouse, P. S. Baran and R. W. Hoffmann, Chem. Soc. Rev., 2009, 38, 3010-3021.

3 For selected reviews, see: (a) A. M. Haydl, B. Breit, T. Liang and M. J. Krische, Angew. Chem. Int. Ed., 2017, 56, 11312-11325; (b) P. Koschker and B. Breit, Acc. Chem. Res., 2016, 49, 15241536; (c) N. J. Adamson and S. J. Malcolmson, ACS Catal., 2020, DOI: 10.1021/acscatal.9b04712.

4 For selected examples, see: (a) H. Zhou, Y. Wang, L. Zhang, M. Cai and S. Luo, J. Am. Chem. Soc., 2017, 139, 3631-3634; (b) H. Zhou, Z. Wei, J. Zhang, H. Yang, C. Xia and G. Jiang, Angew. Chem. Int. Ed., 2017, 56, 1077-1081; (c) T. M. Beck and B. Breit, Angew. Chem. Int. Ed., 2017, 56, 1903-1907; (d) F. A. Cruz and V. M. Dong, J. Am. Chem. Soc., 2017, 139, 1029-1032; (e) F. A. Cruz, Y. Zhu, Q. D. Tercenio, Z. Shen and V. M. Dong, J. Am. Chem. Soc., 2017, 139, 1064110644; (f) A. Leitner, J. Larsen, C. Steffens and J. F. Hartwig, J. Org. Chem., 2004, 69, 75527557; (g) J. S. Marcum, C. C. Roberts, R. S. Manan, T. N. Cervarich and S. J. Meek, J. Am. Chem. Soc., 2017, 139, 15580-15583; (h) L. Cheng, M.-M. Li, L.-J. Xiao, J.-H. Xie and Q.-L. Zhou, J. Am. Chem. Soc., 2018, 140, 11627-11630; (i) N. J. Adamson, K. C. E. Wilbur and S. J. Malcolmson, J. Am. Chem. Soc., 2018, 140, 2761-2764; (j) S. Park, N. J. Adamson and S. J. Malcolmson, Chem. Sci., 2019, 10, 5176-5182; (k) Q. Zhang, H. Yu, L. Shen, T. Tang, D. Dong, W. Chai and W. Zi, J. Am. Chem. Soc., 2019, 141, 14554-14559.

5 G. Hata, K. Takahashi and A. Miyake, J. Org. Chem., 1971, 36, 2116-2123; (b) K. Takahashi, A. Miyake and G. Hata, Bull. Chem. Soc. Jpn., 1972, 45, 1183-1191.

6 For selected examples, see: (a) B. M. Trost, C. Heinemann, X. Ariza and S. Weigand, J. Am. Chem. Soc., 1999, 121, 8667-8668; (b) B. M. Trost and X. Ariza, J. Am. Chem. Soc., 1999, 121, $10727-$ 10737; (x) W. Chen and J. F. Hartwig, J. Am. Chem. Soc., 2013, 135, 2068-2071; H. Zhou, H. Yang, M. Liu, C. Xia and G. Jiang, Org. Lett., 2014, 16, 5350-5353; (x) W. Chen and J. F. Hartwig, J. Am. Chem. Soc., 2014, 136, 377-382; X. Wei, D. Liu, Q. An and W. Zhang, Org. Lett., 2015, 17, 5768-5771; X.-D. Bai, Q.-F. Zhang and Y. He, Chem. Commun., 2019, 55, 5547-5550.

7 (a) B. M. Trost, C. Jäkel and B. Plietker, J. Am. Chem. Soc., 2003, 125, 4438-4439; (b) J. Kuang, S. Parveen and B. Breit, Angew. Chem. Int. Ed., 2017, 56, 8422-8425; (c) W. Ren, Q.-M. Zuo, Y.N. Niu and S.-D. Yang, Org. Lett., 2019, 21, 7956-7960; (d) H.-C. Lin, P.-P. Xie, Z.-Y. Dai, S.Q. Zhang, P.-S. Wang, Y.-G. Chen, T.-C. Wang, X. Hong and L.-Z. Gong, J. Am. Chem. Soc., 2019, 141, 5824-5834. 
8 For selected reviews, see: (a) J. S. Fisk, R. A. Mosey and J. J. Tepe, Chem. Soc. Rev., 2007, 36, 1432-1440; (b) A. E. Metz and M. C. Kozlowski, J. Org. Chem., 2015, 80, 1-7; (b) P. P. de Castro, A. G. Carpanez and G. W. Amarante, Chem.--Eur. J., 2016, 22, 10294-10318; (c) X.-Y. Yu, F. Zhou, W.-J. Xiao and J.-R. Chen, Curr. Catal., 2017, 06, 720-734; (d) I. F. S. Marra, P. P. de Castro and G. W. Amarante, Eur. J. Org. Chem., 2019, 2019, 5830-5855

9 M. J. Goldfogel and S. J. Meek, Chem. Sci., 2016, 7, 4079-4084.

10 T. Chen, Y. Yang, L. Xie, H. Yang, G. Dong, D. Xing, ChemRxiv Preprint, DOI: 10.26434/chemrxiv.7072646.

11 For details, see the Supporting Information.

12 For an elegant example on regiodivergent hydroarylation of isoprene with indole as controlled by different metal-hydride catalysts, see: Y.-C. Hu, D.-W. Ji, C.-Y. Zhao, H. Zheng and Q.-A. Chen, Angew. Chem. Int. Ed., 2019, 58, 5438-5442.

13 For representative examples, see: (a) J. R. Zbieg, E. Yamaguchi, E. L. McInturff and M. J. Krische, Science, 2012, 336, 324; (b) H. Y. Cho and J. P. Morken, J. Am. Chem. Soc., 2008, 130, 1614016141; (c) A. Tortajada, R. Ninokata and R. Martin, J. Am. Chem. Soc., 2018, 140, 2050-2053; (d) Y. Xiong and G. Zhang, J. Am. Chem. Soc., 2018, 140, 2735-2738; (e) C. Li, R. Y. Liu, L. T. Jesikiewicz, Y. Yang, P. Liu and S. L. Buchwald, J. Am. Chem. Soc., 2019, 141, 5062-5070; (f) J. Yang, J. Liu, H. Neumann, R. Franke, R. Jackstell and M. Beller, Science, 2019, 366, 1514-1517. 14 (a) E. J. Smutny, J. Am. Chem. Soc., 1967, 89, 6793-6794; (b) G. Wilke, Angew. Chem. Int. Ed., 1988, 27, 185-206; (c) A. Behr, M. Becker, T. Beckmann, L. Johnen, J. Leschinski and S. Reyer, Angew. Chem. Int. Ed., 2009, 48, 3598-3614.

15 The enantiomeric ratio for $\mathbf{7 a}$ is $66: 34$ when chiral $(R)$-DTBM-SEGPHOS was employed. 